\title{
Cytopathology of Ceratomyxa sp. (Myxosporea) hyper- parasitized with the microsporidan Nosema ceratomyxae
}

\author{
A. Diamant ${ }^{1}$, I. Paperna ${ }^{2}$ \\ ${ }^{1}$ National Center for Mariculture, Israel Oceanographic and Limnological Research Institute, PO Box 1212, Eilat 88-112, Israel \\ ${ }^{2}$ Department of Animal Sciences, Faculty of Agriculture, The Hebrew University of Jerusalem, Rehovot 76-100, Israel
}

\begin{abstract}
The ultrastructural features of Ceratomyxa sp. (Myxosporea) hyperparasitized by the microsporidan Nosema ceratomyxae are reported. The myxosporean is itself a parasite in the gall bladder of rabbitfish (Siganus) from the Red Sea. $N$. ceratomyxae infections are associated with degenerative processes in the myxosporean plasmodium. Sporogenesis of the myxosporean is affected, resulting in formation of aberrant spores or alternatively, total inhibition of sporulation.
\end{abstract}

Pathological conditions in the Myxosporea have rarely been documented, and only 3 cases of microorganisms that specifically infect myxosporeans have been recognized to date. All 3 are microsporidan hyperparasites of coelozoic myxosporean species harbored by marine fish: Nosema marionis (Thelohan, 1895) hyperparasitizes Leptotheca coris from the gall bladder of Mediterranean Coris julis (Labridae) (Stempell 1919); Nosema notabilis Kudo, 1939 hyperparasitizes Ortholinea (Sphaerospora) polymorpha from the urinary bladders of northwest Atlantic Opsanus tau and O. beta (Batrachoididae) (Kudo 1944); and Nosema ceratomyxae Diamant \& Paperna, 1985 which hyperparasitizes Ceratomyxa sp. from the gall bladders of rabbitfish Siganus argenteus, S. luridus and S. rivulatus (Siganidae) from the Red Sea (Diamant \& Paperna 1985). Of these, only $N$. notabilis was reported to be pathogenic to its myxosporean host; a brief light microscopical description of degeneration and hypertrophy of the plasmodium nuclei, accompanied by complete inhibition of sporulation of the myxosporean, was given by Kudo (1944). The present paper describes the cytopathological features associated with $N$. ceratomyxae infection in its myxosporean host, Ceratomyxa sp., which follows a previous study on the developmental sequence of $N$. ceratomyxae (Diamant \& Paperna 1985).

Materials and Methods. Material was obtained from the gall bladders of Siganus argenteus, $S$. luridus and
S. rivulatus. These rabbitfish were caught on the coral reefs near Eilat, Gulf of Aqaba, northern Red Sea. Ceratomyxa and Nosema infections in rabbitfish were determined by direct examination of fresh gall bladder contents by phase contrast microscopy. For electron microscopy, material was processed using the routine described previously (Diamant \& Paperna 1985).

Results and Discussion. A prevalence of $>95 \%$ of Ceratomyxa sp. was found in gall bladders of all 3 rabbitfish species (TL 130 to $430 \mathrm{~mm} ; \quad N=501$ ) examined year-round. However, only in about $15 \%$ of the cases was a concurrent hyperinfection with Nosema ceratomyxae detected. Siganus argenteus was the species most frequently found to harbor $N$. ceratomyxae hyperinfections, and these were found primarily during the winter (December to February).

In normal, uninfected populations of Ceratomyxa sp., various developmental stages of trophozoites were either attached to the gall bladder epithelium or floating freely in the bile. Typically, many of the trophozoites contained pansporoblasts or immature or mature spores (Fig. 1). Numerous free spores were also present. An ultrastructural study of the development of Ceratomyxa sp. in its rabbitfish hosts will be published elsewhere (Diamant \& Paperna unpubl.). However, a brief description is given here for comparative purposes. The plasmodium nucleus was large, contained heterochromatin and sometimes displayed prominent nuclear pores (Fig. 3). The plasmodium cytoplasm had an overall dense appearance and contained numerous vesicles, 0.7 to $1.5 \mu \mathrm{m}$ in diameter, filled with a homogeneous, semi-opaque matter (Fig. 2). These were probably food vacuoles originating from coalescing pinocytotic vesicles. Mitochondria were elongated and tubular, while those inside the sporoblast and developing spores were typically ovate or spherical and contained considerably more matrix. The outer 

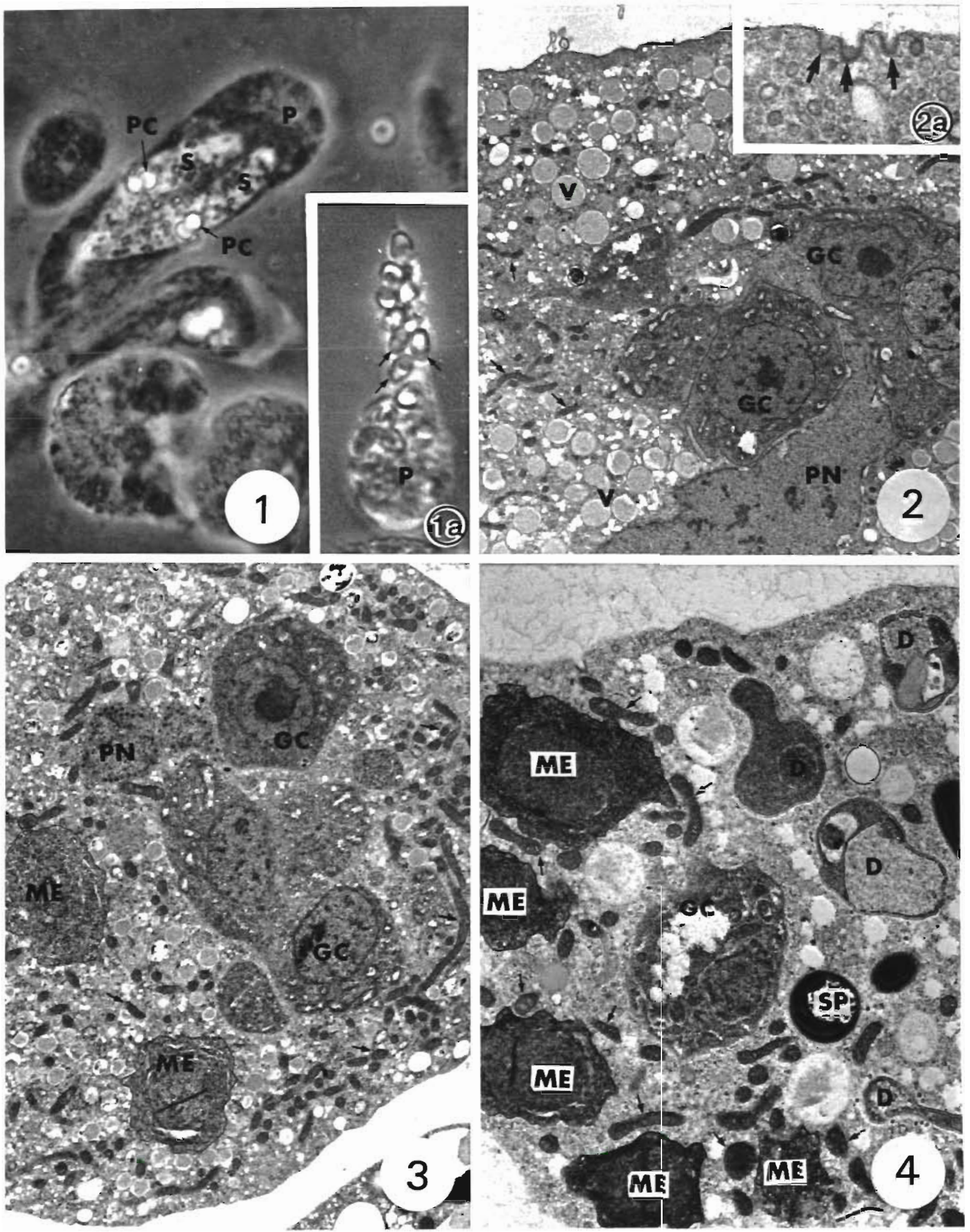
membrane of normal Ceratomyxa sp. trophozoites was generally well defined, and evidence of pinocytosis was often present in the form of minute vesicles near the plasmodial membrane (Fig. 2a).

Trophozoites hyperparasitized with Nosema ceratomyxae typically contained up to 15 or 20 microsporidar spores in light infections (Fig. 1a) but as many as 50 or more could be found in heavily infected plasmodia. Infection with $N$. ceratomyxae clearly affected sporogenesis of the myxosporean; at high prevalence infection levels, when virtually all plasmodia harbored Nosema spores, very few sporulating plasmodia of Ceratomyxa could be detected. While many of the Ceratomyxa trophozoites were normally found attached to the gall bladder epithelium, those harboring $N$. ceratomyxae spores were typically detached and found floating freely in the bile.

Trophozoites harboring Nosema ceratomyxae displayed various stages of degeneration. In newly established infections, changes could hardly be discerned (Fig. 3). As the infection progressed, the plasmodia exhibit increasingly degenerate features (Figs. 4 to 8 ). The plasmodium nucleus was often pyknotic and contained a prominent nucleolus (Fig. 6). The plasmodium membrane displayed gradual loss of density and integrity, and the cytoplasm became increasingly electronlucent (Figs. 6 to 8). Pinocytotic vesicles became scarce and eventually disappeared accompanied finally by signs of vacuolization (Figs. 5 to 8 ). At this point, plasmodial collapse is imminent, and the resulting disintegration of the plasmodial membrane would liberate both host germinative cells as well as parasite spores into the surrounding bile. The coarsely granulated cytoplasm of generative cells showed little change, but often contained lipid droplets or hyaline inclusions and less mitochondria than normal (Figs. 4 and 5).

Developmental stages of Nosema ceratomyxae were often surrounded with tubular mitochondria (Fig. 4), but in some cases large, spherical mitochondria resembling those of the myxosporean pansporoblast (normally not found in the trophozoite cytoplasm) were located adjacent to various developmental stages of the hyperparasite (Fig. 7). Although spore development of the myxosporean did occur in hyperparasitized trophozoites, this was relatively rare, and such spores were evidently aberrant. Interestingly, the microsporidan hyperparasite itself often failed to produce normal spores, yielding bizarre, deformed and abortive sporogonial stages (Figs. 4 to 8 ) (Diamant \& Paperna 1985).

Degenerative processes in hyperparasitized Ceratomyxa sp. plasmodia and the effective inhibition of sporulation processes would suggest that the development of the microsporidan interferes with the sporogenesis of its host. The appearance of relatively large, ovate mitochondria in association with developmental stages of Nosema ceratomyxae in the plasmodial cytoplasm supports this view, since such mitochondria were normally observed only in the myxosporean sporoblast. An association with the myxosporean mitochondria may be required for the normal development of $N$. ceratomyxae, since abnormally developing stages often lacked such associations.

It is noteworthy that Nosema ceratomyxae has an apansporoblastic development, and all stages lie in direct contact with the myxosporean cytoplasm (Diamant \& Paperna 1985). Such an intimate contact could facilitate some form of host response, and interfere with the hyperparasite's development. The high percentage of aberrant sporogonial development found in this microsporidan, as well as in $N$. notabilis (J. Lom pers. comm.), may be due to such a response, triggering a reciprocal interference of sporulation of both parasite and hyperparasite.

Fig. 1. Light microscopy. Plasmodia of Ceratomyxa sp. in a wet smear of fresh bile from Siganus argenteus. One of the plasmodia (P) contains a sporoblast in which 2 spores (S) containing prominent polar capsules (PC) can be seen developing. (Phase contrast, $\times$ 1100). Inset 1a: A plasmodium of Ceratomyxa (P) hyperparasitized by Nosema ceratomyxae. The hyperparasite's spores (arrows) occupy a considerable portion of the plasmodial volume. (Phase contrast, $\times 1300$ )

Figs. 2 to 4. Electron microscopy. Fig. 2. Section through a normally developing, non-parasitized trophozoite of Ceratomyxa sp. containing an early pansporoblast consisting of several generative cells (GC) next to the large, plasmodium nucleus (PN). The cytoplasm is generally dense, particularly the outer, ectoplasmic portion, and contains elongated, tubular mitochondria (small arrows). Numerous spherical, membrane-bound vesicles filled with an amorphous matter are present (V). The generative cells have a dense cytoplasm, packed with ribosomes and small rounded mitochondriae $(\times 9300)$. Inset 2 a: Pinocytotic activity of the plasmodial outer membrane $(\times 32000)$. Fig. 3. Early infection of Ceratomyxa sp. with Nosema ceratomyxae. The overall appearance of the plasmodium is not demonstrably changed (compare with Fig. 2). Two meront (ME) stages of the hyperparasite lie in direct contact with the plasmodium cytoplasm. Note the prominent pores in the plasmodium nucleus membrane (PN). GC: germinative cell ( $\times 8000$ ). Fig. 4. Advanced infection with $N$. ceratomyxae. A generative cell (center) contains a large aggregation of electron-lucent matter There are considerably few cytoplasmic vesicles (compare with Fig. 3) and the cytoplasm is generally less dense and shows increased vacuolation. Sections of 5 meronts (ME), a single spore (SP) and 4 aberrant developmental stages (D) of the hyperparasite can be seen. Note the aggregation of tubular mitochondriae (arrows) around the meronts, and their paucity in the region of the abnormally developing stages ( $\times 11500$ ) 

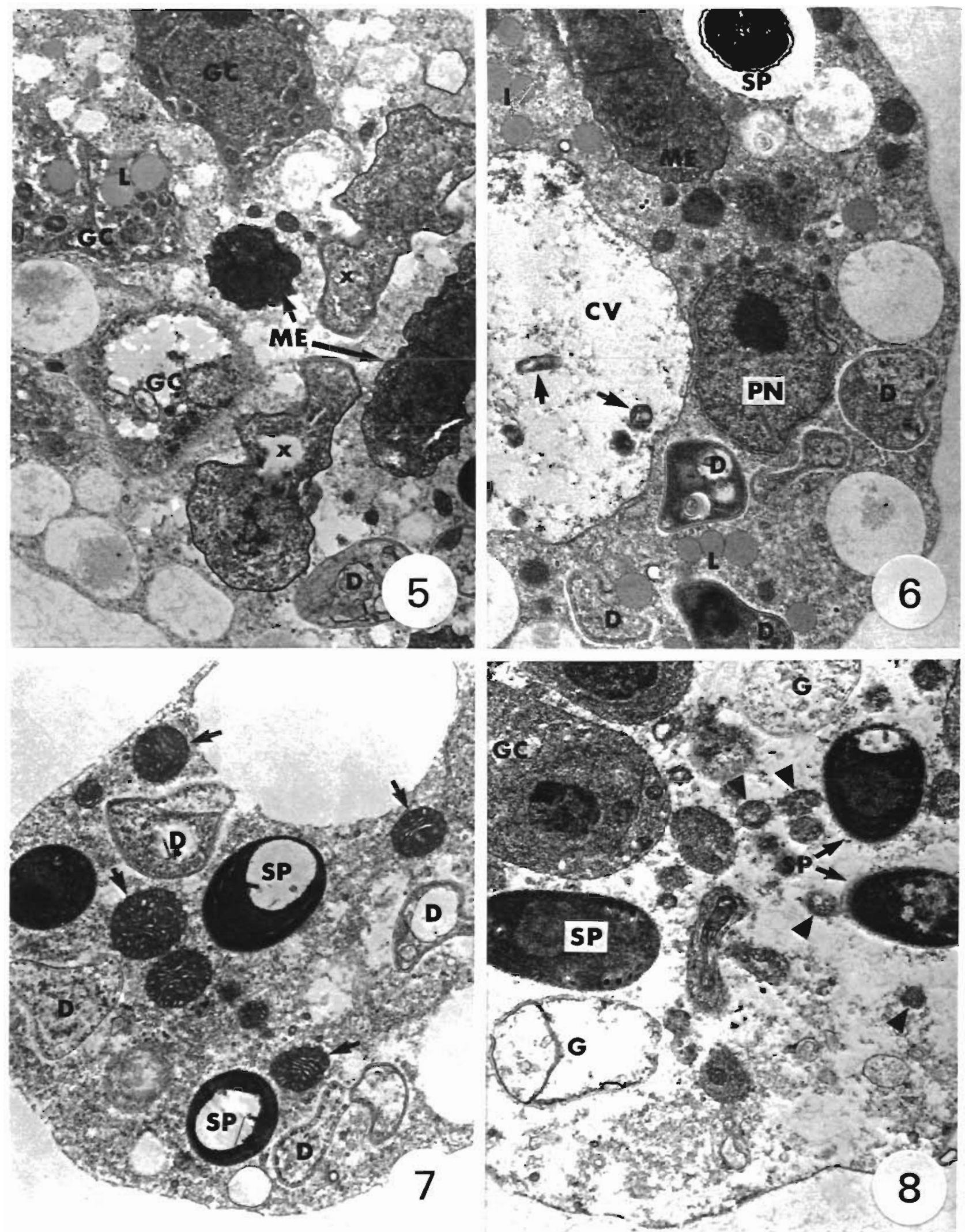
Figs. 5 to 8. Ceratomyxa sp. hyperparasitized by Nosema ceratomyxae. Fig. 5. Advanced stage of plasmodium necrosis. Meronts (ME) and additional developmental stages ( $\mathrm{x}$ ) as well as aberrant manifestations (D) of $N$. ceratomyxae are present. A generative cell (GC) at left displays an early stage of deterioration: lipid droplets (L) and a vacuolated cytoplasm poor in mitochondriae. Another generative cell (at center) contains a large aggregation of amorphic, electron-lucent matter ( $\times 10$ 000). Fig. 6. A. hyperparsitized plasmodium which has developed a large central vacuole (CV) containing mitochondrial remnants (arrows) and electron-dense fragmentary matter. Besides some additional vacuolation of the cytoplasm there is no evidence of the progressing degradation process. D: aberrant stage of $N$. ceratomyxae; L. lipid droplet; ME: meront; PN: plasmodium nucleus; SP: spore ( $\times$ 13 800). Fig. 7. Part of a heavily infected plasmodium, showing immature spores (SP) and several aberrant developmental stages of the hyperparasite (D). The mitochondria are not of the tubular type normally found in the plasmodium cytoplasm, but are large, spherical and contain numerous cristae (arrows). Breakdown of plasmodial cytoplasm and vacuolation are evident $(\times 15000)$. Fig. 8. Severe cytoplasmic degradation associated with $N$. ceratomyxae hyperparasitism in a Ceratomyxa plasmodium. Some developing microsporidan spores (SP) occur alongside 2 generative cells (GC) which appear to be normal. The cytoplasm is extremely electron-lucent and contains degenerative mitochondria (arrowheads), microsporidan 'ghost cells' (G) and fragmentary membraneous structures $(\times 173000)$

\section{LITERATURE CITED}

Diamant, A., Paperna, I. (1985). The development and ultrastructure of Nosema ceratomyxae sp. nov., a microsporidan hyperparasite of the myxosporean Ceratomyxa sp. from Red Sea rabbitfish (Siganidae). Protistologica 21. 249-258
Kudo, R. (1944). Morphology and development of Nosema notabilis Kudo. Ill biol. Monogr. 20: 1-83

Stempell, W. (1919). Untersuchungen über Leptotheca coris sp. nov. und das in dieser schmarotzende Nosema marionis Thelohan. Arch. Protistenkd. 40: 113-157

Responsible Subject Editor: Dr A. K. Sparks; accepted for printing on August 19, 1988 